\title{
ARTISTIC RESEARCH: THE THOUGHTS AND IDEAS OF MIKA HANNULA
}

\author{
Guntur \\ Indonesian Institute of the Arts Surakarta, Indonesia \\ E-mail: guntur@isi-ska.ac.id
}

\begin{abstract}
This paper is a review of the thoughts and ideas of Mika Hannula presented in his book Artistic Research: Theories, Methods, and Practices. As its title indicates, this book discusses artistic research, specifically related to the theories, methods, and practices of its implementation. In this paper the writer attempts to review: the urgency of artistic research, the philosophical foundations of artistic research, artistic research and science, epistemology and axiology, methodology of artistic research, and its expediency and guidelines for use in art research.
\end{abstract}

Keywords: Research, artistic, theory, method, and practice.

\begin{abstract}
ABSTRAK
Artikel ini merupakan review dari pemikiran dan ide Mika Hannula yang disajikan dalam bukunya Artistic Research: Theories, Methods, and Practices. Sesuai dengan judulnya, buku ini membahas tentang penelitian artistik, khususnya yang berkaitan dengan teori, metode, praktik dan pelaksanaannya. Dalam tulisan ini, penulis mencoba mengkaji: urgensi penelitian artistik, landasan filosofis penelitian artistik, penelitian dan sains artistik, epistemologi dan aksiologi, metodologi penelitian artistik, serta kemanfaatan dan pedoman penggunaannya dalam penelitian seni rupa.
\end{abstract}

Kata kunci: Penelitian, artistik, teori, metode, and praktik.

\section{Introduction}

The book to be reviewed in this paper is entitled Artistic Research: Theories, Methods and Practices. It consists of six chapters: introduction, two metaphors and their consequences, methodological faces of artistic research, artistic research in practice, the meaning of artistic research, and conclusion. In reviewing this book, I use several fundamental questions that are needed in order to conduct the reading: What is artistic research? What is its philosophical basis? What is the epistemological dimension of artistic research? What is its methodology? What are 


\section{Artistic}

some examples of concept as its method of analysis? Through these five questions, the reader will gain a brief overview of the content of this book, the problems of its underlying methodology, and its benefits for art research, whether research for art creation or art studies, as is generally found in art colleges in Indonesia.

This book is an elaboration of an earlier book, Guidelines for Artistic Research, written in 2003 by Mika Hannula, whose interests lie in ethical aspects of art and contemporary culture. The title of the book was subsequently changed to Artistic Research: theories, methods and practices because of the involvement of two other writers from different backgrounds. These writers are Juha Suoranta, who concentrates on the question of (qualitative) research methodology, critical pedagogy, and political sociology of education; and Tere Vadén, who specializes in the philosophy of science, which generally gives rise to questions about the identity and role of science in contemporary society. All of these interests, if simplified, are branches of philosophy, whether ethical, methodological, or epistemological, and which subsequently converge in a special area - namely artistic research.

What is artistic research? The question that needs to be asked first in order to gain clarity about the direction of 'artistic research' is: 'what is artistic?' Why do artistic problems need to be researched? The book in question does not explain what is meant by the word artistic. We will therefore use the general assumption, namely that artistic is one of the main issues in aesthetics, which refers to the activity of creating a work of art, and places it in an academic context, as the process and product of art. Artistic research is a research process in order to produce (a work of) art. To answer the second question, why do artistic problems need to be researched? Because the activity of creating art has produced meaning that is related to the life of society, which Tere Vadén refers to specifically as contemporary society. We can therefore simplify it as research about art.

Returning to the original question, what is artistic research? We are given an

indication of the answer to this question in the sub-title of this book itself, namely that artistic research is concerned with the theories, methods, and practices that are 
needed to conduct the type of research that is referred to as artistic. We can immediately place this book in alignment with methodology, more specifically the 'faces' of methodology in art research, because this book is concerned with the methods - ways of knowing the artistic object of the research - which are different from those used in scientific research such as the history of art and the sociology of art. Why are art history and sociology used as examples of scientific research? Because scientific ideas form the basis and direction of research on the history and sociology of art, seeking to find certainty, regularity, and objectivity to produce universal knowledge. Artistic research, meanwhile, leans more towards selfreflection and a process of self-criticism of the person taking part in the production of meaning in contemporary art (Mika Hannula, Suoranta, \& Vadén, 2005). In other words, it is a process of subjectivity. In the situation of artistic practice, this book is one of the early books that endeavours to position the artist as the researcher and the art student as the artistic researcher - in order to escape the uncertainties of methodology that have been traditionalized by scientific research and social studies.

\section{Why has Artistic Research Appeared?}

Is classical methodology insufficient? Why has artistic research appeared? Can other research traditions not be used in the artistic domain? When this book was written, research pointing in the direction of artistic research had already been carried out for more than twelve years. The term artistic research itself was first used by Christopher Frayling in his scholarly paper entitled "Research in Art and Design", which was published by the Royal College of Art.

Since that time, the need to research artistic objects has been haunted by the questions, how and in what frame should artistic research be conducted? The requirements clearly lie in the methodology. What kind of methodology, then, is suitable and not harmful to the artistic object? Because there are numerous kinds of art, and varieties of artistic expression, ranging from music to theatre, from visual art to visual culture. On one hand, contemporary art is experiencing increasingly rapid developments, while the basis of artistic methodology is still in the process of 


\section{Artistic}

developing. As a result, 'artistic researchers' sometimes look at 'research methods' from other research traditions, such as the scientific methods used in the tradition of classical methodology.

The tradition of classical methodology places more emphasis on testing a hypothesis using a deductive method, such as a method of physical testing through a laboratory experiment with a quantitative analysis. The criteria for research qualities with classical scientific methodology are: objectivity, reliability, and validity. The results are considered to be highly convincing because any empathy towards the research object is removed by creating as great a distance as possible with the research object so that the researcher is not in any way influenced by the object to be researched. There is also another type of methodology which is reflective and dialectical in nature, allowing space for empathy and dialectic interaction between the researcher and the object researched in order to re-comprehend (reconstruct) the reality being researched. The method used is qualitative, one example being participant observation, in which the object (the person who is the object, not the respondent) being studied becomes a participant. This means that the 'object' researched also feels interested and subsequently takes part in the research. The understanding of a reality or discovery of validity of a research study is the result of an interaction between the researcher and the research object. The criteria for research qualities traditionalized with a qualitative method are: originality or authenticity, meaning that the study is not fabricated or manipulated; and reflexivity, which looks at how far the research findings that have become scientific knowledge are an authentic reflection of the reality that is experienced by the social agent. What is sought after in these two paradigms and approaches, objectivism and subjectivism, qualitative and qualitative, is only one thing - new knowledge.

In an academic situation, where artistic methodology is still in the process of development, 'artistic researchers' in their confusion, endeavour to hold onto the belief that the accumulation of knowledge in the artistic domain is a form of research. This accumulation of knowledge is the interpretation of and empathy 
towards the arts. Various kinds of works of art form an accumulation of knowledge over the course of time, because the entity of 'knowledge' has already adhered firmly to the works of art, and as such, the artistic process in creating a work of art becomes an activity of research. In short, in this form of artistic methodology, which is not known in the scientific tradition, art is the result of the research. Based on this assumption, artistic research encompasses the artist's practices in creating a work of art and research of the creative process becomes an activity to increase 'knowledge', which is then passed into a data base as an accumulation of knowledge. Regardless, all ideas about artistic research are relatively new and its forms and principles are not yet well established.

The idea of research that breaks free from scientific traditions, from the rational and objective, though not in entirety, is both a challenge and an opportunity because it offers a fair chance to develop its own methodology, free from excessive formalities, and therefore, the accumulation of knowledge in the artistic domain can still be constructed through practice. In addition, specific artistic connections in research can establish dynamic connections with other types of knowledge. In this case, that means constructing multi-disciplinary artistic research that is framed by practices in contemporary culture by opening the boundaries between mediums of expression and methods for producing knowledge.

The case study in this book takes the phenomena of contemporary art and visual culture, with the awareness that the artistic domain has its own distinct features, ranging from music to theatre, from dance to design, fashion, mass culture, film, etc. This book accentuates the possibilities, challenges, and demands of artistic research as an area that is currently articulating its criteria of research, namely individual characteristics and practices, and the possibility for it to be applied to a broader community. The viewpoint that emerges is a combination of research approaches and specific characteristics of artistic practices. The assumption in this artistic research is that the artist is the 'researcher' and positions the 'research' as a creative process in order to obtain knowledge, or vice versa. A researcher who 


\section{Artistic}

researches art is an 'artist' who pays attention to the epistemological aspect, or in other words, the relationship between the researcher and the research object is uniquely different to that of scientific research. The knowledge produced through artistic research is different from the knowledge produced using the methods of scientific research. Both use theories of knowledge which are subsequently applied to a method that can be used to observe the object of the research, in order to answer the question of how the knowledge is obtained, or in other words the methodology.

\subsection{The Need and Basic Philosophy of Artistic Research}

Every research study has its own assumptions about the object of the research, and these assumptions about the object or social reality being researched are ontological in nature. Ontology is concerned with the essence of reality, finding general principles from what already exists in order to achieve the status of truth or fact. Artistic research puts forward a non-classical epistemological and ontological model (Mika Hannula et al., 2005). Classical epistemology views reality as being truly objective and existing outside the researcher's self, and as far as possible, the researcher keeps a distance from the research object. Classical ontology views reality as being regulated by certain principles that apply universally, even though the validity of the knowledge itself is obtained probabilistically. This objective and universal status of knowledge is avoided in artistic research, which is more accepting of the subjective view that knowledge is the result of interaction between the researcher and the research object, or that the relationship between the researcher and the research object is connected by certain values.

The term artistic research has a number of different meanings, connotations, and implications due to the fact that it is still in the process of seeking a fixed definition. To the researcher, this presents an intellectual challenge. Artistic research is participating in the development of a theoretical basis, as well as enriching professional practices, guiding variations of knowledge and skills, and enabling the crossing over of boundaries between different disciplines and forms. Below are a number of general features that characterize artistic research (Mika Hannula et al., 
2005) : (a) The work of art is the focal point; (b) Artistic experientiality is the essence of the research, depending upon how it is transmitted and transmits meaning. Experientiality is defined as relating to, deriving from, or providing experience; empirical (referring to the form of experiential knowledge) (Merriam-Webster, 2020) or generating a quasi-mimesis of real-life experience, and used to define narrativity in terms of human experience (Lyytikäinen, 2012) ; (c) Artistic research should be a self-reflection, self-criticism, and directed communication; (d) The place of artistic research is in a historical and disciplinary context, positioning the research according to actions and goals, and at the same time focusing more on a particular field; (e) Use of different research methods, presentation methods, communication tools, and commitment to the needs of a particular case; (f) Emphasis on productivity and the need for dynamic research in a group situation, in a collective endeavour to provide a critical environment, create a protective sphere for experiment, and ensure the ability to share ideas and emotions; and (g) Hermeneutic, interpretative quality of research.

Consequently, artistic research is related to a series of goals, which make its relevance evident. These are: (1) Producing information that serves practice, such as from an ecological, psychological, social, cultural, economic, political, technical, or functional perspective; (2) Developing a method that is related, for instance, to a creative work process, defining criteria for making an evaluation, or modelling and illustrating a design; (3) Increasing understanding between art and its social issues, culture, and pedagogical context helps the position of an artist's work in a broader context, including historical and political development; (4) Interpreting a work of art as a cultural, political, and pedagogical product; (5) Producing knowledge about the social, psychological-social, and psychological, as well as political and pedagogical meaning, so as to develop artistic activities (education, living environment, quality of life); (6) Analyze current art critically; objects which, amongst others, offer an understanding in the relationship between art and technological developments, between art and economic developments, in power relations, and so on; (7) Reunderstanding and questioning the role of artists, the consequences of which are not 


\section{Artistic}

only in the death of the creator but also in the significant increase of collaborative artistic endeavours, as well as questioning the role of the artist in general society (Mika Hannula et al., 2005).

Artistic research can be used to study the practices of individuals and groups. It may focus on a work of art or its meaning. The fact that artistic research is becoming increasingly independent is hoped will offer the opportunity for critical reflection in the research community. Its goal is to produce new kinds of information that are not introspective but combinative, searching for fresh, new connections in the research field.

\subsection{Artistic Research in the Shadows of Science}

There is no general philosophical-methodological basis in artistic research. The original commitments and foundations of artistic research can be compared and even found to be contradictory, whether ontologically, epistemologically, or practically. There are two reasons for this. First, diversity is needed to promote research productivity. Second, the theoretical background of artistic research is intersubjective and scientific but displays scientific maturity (Mika Hannula et al., 2005). What is being sought from this intersubjectivity and coherence is to show that artistic research begins with something subjective, an interest that enables the subjectivity to communicate in 'scholarly' ways and principles with the findings, has logical relations, with 'orientation' to transparency and criticism.

In order to describe these methodological conditions, the writers use two metaphors: democracy of experiences and methodological abundance. The epistemological and ontological model proposed is non-classical and 'anarchistic' (Mika Hannula et al., 2005). Non-classical scientific methodology can be understood to mean scientific ideals that are open and critical, and this cannot be achieved with methods that are used in 'traditional' natural science. Natural science is a term that refers to the group of sciences in which the objects are natural objects possessing laws that are fixed and general, and can be applied at any time and in any place. The term 'anarchistic', meanwhile, is used to describe a world that is diverse, chaotic, 
and full of surprises, and for this reason, applying a single method to all of this would simply be deceiving oneself (Mika Hannula et al., 2005). Diversity has already been erased in such an a priori method, so this 'ailing' epistemology of scientific knowledge needs to be treated with anarchism, and only with an 'anarchistic' attitude can this critical and open scientific orientation be continued.

\subsection{Democracy of Experiences}

How can art and research go together? Long roots already exist - at least the occidental roots in classical Greece which systematically explored art and research on a continual basis. This tradition produced the fundamental idea which separated different ways of thought and actions, and formed 'different' human beings in the work of art and research. As a consequence, the practices, teaching, and results of art and research were separated. This resulted in a dualistic division in Western experience and this also includes individual experiences (Mika Hannula et al., 2005). These experiences, which have been kept separate from the beginning, and cannot be joined together, illustrate the relationship between art and research.

In order to oppose this background, the status of experience requires a 'purpose', namely that experience is a 'matter of life' that does not have the will to isolate itself. If art and research were to separate, it would not happen naturally. It would require an effort to achieve non-dualistic and non-binary dialogue between the areas of art and research experiences. In connection with experience, in art and research, the influences of experience on objectivity and subjectivity, openness and criticism, need to be reconciled. It is necessary to characterize the democracy of experience in an endeavour to provide a starting point for epistemological and ontological coherence, which will then show how and why artistic research can become a part of a mature scientific practice (Mika Hannula et al., 2005).

The democracy of experience needs to learn from the history of science, or the demarcation of science. It is the nature and authority of science and research to correct itself, and also the power of 'experience'. Science does not depend on authority, nor does it allow the claim of a particular finding to pass by without close 


\section{Artistic}

and critical scrutiny. Therefore, rigorous criticism is an essential criterion for regulating the separation of science from religion, technology, and art, and if necessary, philosophy (Mika Hannula et al., 2005).

How then to fulfil the spirit of science that is open and able to apply selfreflection to artistic research, as well as being able to understand the meaning of human experience? This is apparently where the criteria of 'research' and 'experientiality' come together. The democracy of experiences is a perspective in which there is no area of experience outside the critical principle that touches on all aspects of experience. Scientific maturity is characterized by an abundance of theories, interpretations, and paradigms. Only science that accepts openness and is willing to accept criticism can be called science, and not that with a single paradigm.

\subsection{Methodological Abundance}

The enthusiasm of artistic researchers has determined its methodology. It has been claimed that in the case of artistic research, methodological abundance is a productive approach, using new methods to produce new scientific findings. This claim is based on the idea that experience plays an important role in artistic research. In addition, in the spirit of democracy of experience, all fields of experience play a role in the hermeneutic spiral of (artistic) experiences. The goal is to show and understand that all abstract structures - methods, including methodologies - have boundaries and limitations. The richness of features of reality is not organized according to a model of beauty but requires an anarchistic starting point.

Experiential democracy and abundance of theories are considered suitable as the foundation of practice-based research, such as the experiences of an artist and the skilled behaviour of practitioners. There are two reasons for this: first, practice-based research requires access to experience in all its types and variations. Second, the role of practice-based research, in artistic and scientific communities, demands ways that are self-reflective and self-critical. Taking the existence of experience and consciousness seriously also means taking into consideration the possibility of the academic effect, even when the theories of practice-based research in the arts have 
an effect on artistic experiences in the future, whether individual or collective. Practice-based research in the arts cannot be considered neutral in terms of its art practices or skills.

What then is its connection with experience and art? Art experience cannot be viewed with methods of natural science, because the expressis verbis factor closes all the possible doors to practice-based research. Art experience in practice-based research does not use natural science concepts. Experientiality, openness, possibilities to share and communicate artistic competence are in no way facts of universality in natural science. It is this distinction from natural science that reinforces the fact that artistic research, whether practice-based or otherwise, is full of subjects, objects, observation, individuation, and so on, which are at the center of artistic practice, skills, and research - and should not be bound to methodological views that make a clear separation between the experiencing subject and the object that is observed as a condition of inquiry (Mika Hannula et al., 2005).

Artistic experience is seen as a continuum, a sustainable experience, and is therefore best approached in a hermeneutical way. In practice-based research, experience looks at experience and thus produces a new experience. Hence, critical in the context of experiential democracy means multi-dimensional criticism, methodological pluralism, and circularity of experience, while at the same time recognizing the ethical dimension of hermeneutics. Ideals of openness are achieved by making explicit the relationship between theoretical experience and artistic experience, a relationship that is validated methodologically. In Hermeneutics, openness does not depend on the presumption of universality but endeavours to increase intersubjectivity.

\section{Seeking an Epistemological and Axiological Way Out}

We can see that in fact the shadows of science in the search for artistic methodology are quite powerful. A way out is needed from the objectivism traditionalized by natural science and the scientific relativism traditionalized by hermeneutics. In artistic research, the researcher tries to be as open as possible in 


\section{Artistic}

relation to the object of the research, with the aim of realizing his own suppositions, desires, interests, and if possible fears. Researching in this way is an event that emerges gradually and in stages, one of which aims to look at the 'what' and 'why' of the issues and problems addressed in each case, and 'forces' the researcher to think about who and where he is. This means, too, that the writer, researcher, listener, and person experiencing must have the courage to take his own personal standpoint.

Artistic research aims to avoid objectivism, while not stopping either at relativism, but hoping to surpass the two in ethical matters. The ethical problems connected to each paradigm need to be united in an ethical encounter. In this way, it is hoped that artistic research can be defined as a democracy of experiences that demands multiple variations of method, and the different parties can meet each other reciprocally.

The goals of research methodology based on democracy of experiences is specifically to show how artistic experiences and scientific theorization interact with each other, guide each other, and influence each other, thus creating critical research. Research must focus on how experientiality in a particular case and event guides the theoretical formation of knowledge, and vice versa, and how theories born from reading, thinking, and debate give direction to artistic experience. The experiential continuum should be approached hermeneutically. In artistic research, experience studies experience, and produces new experiences. Hermeneutics is not simply a search for truth and competence of interpretation but also the recognition of ambiguity, for the sake of continuous critique (Mika Hannula et al., 2005).

In hermeneutics, the person who conducts the research, the researcher as "I" or perhaps "we" is always presents in the event. As artists and art researchers, we cannot separate ourselves and our practices into two worlds: the world of experience and the "real" world that already exists. We may refer to this as experience interpreting experience, and arrange it into a new form that can be accessed by others. Researchers and artists are on a continuous flux of experience (Mika Hannula 
et al., 2005).

\subsection{Methodological Faces of Artistic Research}

In the previous section, it has already been mentioned that artistic research aims to avoid objectivism, while not wishing to stop at relativism, but instead surpassing the two of them. The previous section explains that artistic research wishes to surpass both objectivism and relativism by taking an ethical position. How is the problem of ethics connected to methodology? There is no need for "universal rationality", only a sufficient reason to strive towards a "second choice" in a "third space". Another choice in another room. What is the second choice, where is the third room? An artistic researcher is a person who experiences, who must have the courage to take a personal standpoint, to take up a position of subjectivity in a community with its own tradition. A researcher becomes a part of the ethics, values, and morals that cannot be separated from the research object.

Methodological pluralism is an epistemological starting point and the basis of the democracy of experiences for artistic research. The question is, what are the suitable and beneficial methods in artistic research? How are they related to the methodological criteria mentioned above? Artistic research is open to a variety of methods, the important thing being that the research questions can be answered. Usually the best approach is one that is in accordance with hermeneutical knowledge and the interests that make up the research. The results obtained are a new interpretation. There are five methodologies that can be discussed: conversation and dialogue, analysis of media representations and media objects, collaborative case studies, ethnography and intervention, and practice-based research (Mika Hannula et al., 2005).

\subsection{Conversation and Dialogue}

Conversation is different from a questionnaire, dialogue is different from a survey. Who knows, a respondent may fill out a questionnaire according to his feelings about life, and can his feelings about life be converted into a variable. The quality of a problem may be explored reciprocally and in depth with dialogue, not so 


\section{Artistic}

with a survey. A problem is investigated with a method that identifies the known and unknown, the named and unnamed, the unconscious and conscious, and the uncertain and certain. Sometimes knowledge emerges, startles, in a way that announces itself not in a way of 'interrogation'. The dialectic of the unattainable can be applied as a tool of artistic research with consideration as to how language is used to determine what is being talked about, what is being looked at, and how it is viewed. The general assumption is that the world is constructed (Mika Hannula et al., 2005).

A research tool must pay attention to the situation: who is writing, for what, and how. This usually influences the entire research process. The theory of writing can be perceived in a methodological trinity consisting of the ideas of contextuality, indexicality, and autobiography. Contextuality refers to the contexts or frameworks of an activity where (social) reality is clear, through which meaning is deconstructed. Indexicality is understood as an expression related to history and biographical data. This means that a person must know who is speaking, when and where something is discussed, and what was discussed before the issue arose, and what it is connected to in a broader context. Autobiography connects contextuality and ideality with a narrative-experiential whole, such as consequence or contradiction, the plot of a story and how it progresses.

\subsection{Analysis of Media Representations and Media Objects}

The general question here is how the viewpoint of artistic research responds to the claim that art is used as a popular culture, in particular for pleasure and therapeutic experience. Artistic research aims to show the difference between media representations in a comparative study. Research objects may include: performances, events, films, posters, animations, advertisements, comics, hobby magazines, tabloids, toys, computer games, and so on. The value of the research is that it learns how they are perceived as entities that present or represent the reality of human life. Both art and popular performances are material for learning to create attitudes, habits of thought, and modes of action in contemporary culture.

The concepts of objectification and alienation can be considered in relation to 
representation. Another analysis that can be performed is reception analysis, which is an observation of how (popular) people read popular cultural products, which means studying the meaning that these people assign to different artefacts. A data-base analysis may also be performed to investigate how researchers read popular cultural products. Other forms of analysis include analysis of themes, usually in films. The various theories that can be used as tools of analysis are semiotic analysis, studies of visual narrative rhetoric, aesthetics, and genre analysis.

\subsection{Collaborative Case Studies}

A collaborative case study is the name given to an approach which tries in one way or another to influence the research object by including people other than the researchers in the research. The researchers and non-researchers work together to solve problems observed in practices, to find solutions that are evaluated on a continual basis. The opposite of this type of research is an approach that positions research as an open activity, in which the person being researched is told the intention of the research and asked to cooperate - with the aim of influencing the person's life in a positive manner. In this kind of research the distance with the research object may be adjusted in one of two ways: merging together or creating a greater distance. Several different terms are used to describe this kind of research, such as action research or influence research, another option being participatory research.

\subsection{Ethnography and Intervention}

Ethnography is a form of observation which takes place along with the social reality of the natural phenomenon being researched. The root of ethnography is anthropology which primarily studies foreign cultures. Ethnography is a way of learning through experience. The researcher lives for a period of time in the day to day life of the community being studied. The goal is to study the culture, modes of thought, and actions - from inside, endeavouring to observe comprehensively and not simplify into variables, as in quantitative research. Comprehensive means attempting to avoid impressions and excessive subjectivity, by presenting the reader 


\section{Artistic}

with various viewpoints of the research object as intimately as possible. Put simply, ethnography is an activity in which people are studied in their daily situation, as opposed to experimental research in which the researcher creates the setting.

This research has more or less a direct influence on people's consciousness, and this is prepared as a target in artistic research. Types of art phenomena that are interesting to study include urban arts, such as banderols, stickers, t-shirts, and posters, not in the sense of their actions or meanings produced, but rather urban art as something that is scattered, exists in public spaces, takes the conditions of a space and negotiates its needs and opportunities with various parties. This may include depending on official or social permits, and financing, as well as being associated with spontaneity, social messages, and form. Intervention with a social message focuses on public spaces rather than urban spaces.

\subsection{Practice-based Research}

Artistic research has a single goal, which may be achieved using different ways, and which is a direct reflective connection with the field of practice. The aim of artistic research is to look for the interesting side of the research object. This presents a challenge to develop a suitable method for explaining and evaluating the unique nature of a practice. Sometimes practice is opposed to theory and does not take into consideration the fact that the creation of theory occurs together with practice. The difference between theory and practice is best viewed fundamentally in terms of the quality of human experience and knowledge (Mika Hannula et al., 2005).

This kind of research attempts to look at the skills and practices of the artist in the form of his own area, his regional ontology, which distinguishes him from, say, the practice of a doctor or teacher in that it is directed more towards the way of doing something or acting in an appropriate manner, which may be considered routine and self-evident.

An important starting point in perceiving artistic research is the problematization of some artistic practices rather than the 'operationalization' of 
certain theories of theoretical viewpoints. In other words, practice is seen as something that is interesting in itself so that the research of practice requires the application of a certain method, such as ethnography. Other practice-based research includes design-based research, in which the object of interest is the artist's practice, but the artist-researcher does not concentrate on the theorization of the practice, instead using design as a research tool as a way of achieving a primary relationship with the phenomenon being researched. The form of knowledge and process of knowing are shaped by the dialogical relationship between conceptual elements (elements that theorize the practice) and material elements (design or experimental design), which subsequently go on to provide a solution to the problem. The main tools of the artist - plans and sketches - then become research tools or experimental tools. The artist uses sketches in the way that empirical research uses questionnaires. Here, design represents the empirical data of design-based research.

\subsection{Artistic Research Practice}

In this section we are being led towards to the simulation of artistic research practices. Some of the philosophical questions in the previous sections are reduced to pragmatic questions. For example: What is the use of (something that is considered important and is the subject of a research study) in life? How do we present our experience of a practice in the right way? How can our thoughts about a practice be applied, be 'sold', so as to change the experience of other people and be called research?

Beginning an artistic research study with a hermeneutic attitude, by applying a method not as a means of demarcating the research but to break down, guide, and frame the research, is the basis of artistic research. Based on the point of view of the researcher and the reader, at least six factors can be determined, as follows: (1) Clarifying the subject and beginning the research. The conditions for research are that it must be clear in its intentions and approach. What is being researched, why is it of interest, and what are the reasons behind it? (2) Breaking down presuppositions related to the subject matter and viewpoint of the research. Selecting and separating 


\section{Artistic}

discourse that is one-sided and making a critique of it. (3) Choosing research tools and subject matter of which the researcher has a good command. How and why are certain tools chosen? This shows preliminary knowledge of how the research subject is to be treated. (4) Presentation of literature. The goals of presenting artistic research should be logical, persuasive, honest, economic, and use a particular writing style and method of presentation. (5) Evaluation of final results. The method is a research map, which if necessary gathers and presents experiences that arise during the research. (6) Re-perception of research practices and a preliminary study is needed for artistic research. This is necessary if the research object is completely new to the researcher.

Table 1. Basic model of artistic research

\begin{tabular}{|l|c|c|}
\hline \multirow{5}{*}{ Sphere } & External viewpoint & Internal viewpoint \\
\cline { 2 - 3 } Rules of Sphere & $\begin{array}{c}\text { Social semiosis, public } \\
\text { sphere, politics }\end{array}$ & $\begin{array}{c}\text { Research methodology, } \\
\text { sphere of research }\end{array}$ \\
\cline { 2 - 3 } & $\begin{array}{c}\text { Persuasiveness, conceptual } \\
\text { innovation } \\
\text { hegemonic interpretation }\end{array}$ & $\begin{array}{c}\text { Verbalization (reflection, } \\
\text { abstraction, interpretation) }\end{array}$ \\
\cline { 2 - 3 } & $\begin{array}{c}\text { Changing the object as a } \\
\text { work of art, 尔 a text,... }\end{array}$ \\
\hline $\begin{array}{c}\text { Reception of research } \\
\text { object }\end{array}$ & $\begin{array}{c}\text { Research object } \\
\text { (phenomenon, event, } \\
\text { process,...) }\end{array}$ \\
\hline
\end{tabular}

\subsection{Relevance of Artistic Research}

Artistic research is the intellectual pleasure of creating new knowledge, or in other words, an activity which challenges and exposes, opens and moves - to consider who we are, where we are, and how we are. The answer to a research question depends on the effort of the researcher in achieving the research goals. Artistic research is felt to be meaningful when it focuses on research questions that are considered important. The beginning of every research should open with a question as a way of observing relationships between one thing and another. The success of research is a matter of finding a critical place that can support the research, while at the same time being meaningful to others as well as those who are 
doing the work. In this instance, a researcher is similar to a writer.

\subsection{Reliability in Artistic Research}

The meaning of reliability in artistic research is that the research is intersubjective; in other words it communicates coherently with the reader. There are five important points in artistic research: (1) Presenting the research context and determining the main problem. It is useful for a researcher who has already chosen a subject to be wary of his connection to a particular artistic tradition. Presenting the main problem may help to open up the problem points that are related to professional practices, as well as being critical towards the point of view of developing these practices. (2) Credibility and clarity. An integral aspect of scientific research is its presentation and theoretical perspective, and how the researcher approaches the research object and data, thereby laying the foundations for a conclusion. The researcher presents data, makes an interpretation that the reader can follow as a working progress that forms the basis for the coming conclusion. Furthermore, in artistic research the researcher separates the process into several stages that can be followed, and also provides information, for example through sketches, a design diary (in the form of an analysis) of the journey that has guided the choices made. (3) Internal coherence and persuasive research. Persuasiveness can be achieved with the presentation of a rhetorical model such as writing. In the artistic process, for example, the researcher may include "original material" such as daily notes or sketches, which allow the reader the opportunity to formulate his own interpretation and conclusion, and if necessary, to communicate them. (4) Usability, transferability, and new value of the results. In research it should be taken into consideration how the results can be broadened or transferred to other situations, such as renewing practices and skills. The aim may be to renew artistic practices, produce models for solutions that can be reflected in and applied to practices. The writer should underline his own artistic qualities, the qualities that are essential for demarcation of the subject. (5) Meaning and importance of the results of artistic research to the research community. Research should have the ability to highlight the ways in which 


\section{Artistic}

its results can be reconnected to the community that understands its own skills. The picture presented in the research about the skills and the differences in dimension should not only increase theoretical knowledge but also arrange the skills in new ways (for example: practices, education, and institutions).

\section{Conclusion}

The book reviewed does not provide an explanation about the meaning of epistemology, ontology, and methodology. The reader is perceived to already know the difference between the three. Therefore, in this discussion the writer includes a brief description of these terms. It is evident that determining the methodology for artistic research is shadowed by natural science, which seeks to find a way out through hermeneutic relativism, and continues in a critical direction while not ignoring scientific principles, so as to become open and critical in order to produce a text that is open, divergent, and not only provides information but also serves as a conscious and corrective action. Theoretical abundance is regarded as being suitable for the foundation of practice-based research, because practice-based research requires access to experience in all its different variations. Thus, several methods are needed to process this intersubjectivity. In addition, the role of practice-based research in artistic and scientific communities demands the use of self-reflective and self-critical methods. Taking the existence of experience and consciousness seriously also means taking into consideration the possibility of the academic effect, even when the theories of practice-based research in the arts have an effect on artistic experiences in the future, whether individual or collective.

In order to add to the existing list of the perspectives of people conducting research, we add a list for institutions: (1) The work of institutions should be based on self-definition and self-criticism. Targets should be formulated such as the quality of the research, not the method, and people should promote relations with other institutions (for example financial institutions). (2) Offer the opportunity for participation, experimentation, risk-taking - avoiding a final set-up which establishes research methods and ways of presenting research results. In other words, there 
should be opportunities for unlimited creativity and experimentation. Criticism, openness, and tolerance are not only for students but for all levels of educational institutions. (3) Encourage doctoral students to work together, questioning and discussing basic principles, such as: what is research, why is it important, why does it need to be completed? These questions serve as constructive criticism and open the way for progress. (4) Explain one particular goal, such as: what is the purpose of an academic title? And what is its consequence? (5) Have the courage to believe the fact that artistic research creates itself, step by step.

This book on artistic research can be said to offer a basic mapping of the scientific philosophy and methodology needed for determining the type of methodology to be used in research on artistic practices. The intentions of the theoretical background of a theoretical study show two things. First, the diversity and consequences of ethics are positive things that promote research productivity. Second, the theoretical background of artistic research is intersubjective and scientifically mature, and does not lack the principles of the spirit of science itself.

Another benefit the authors of this book hope for is that it provokes an interest in developing conditions that can be trusted by artistic research to develop evaluation practices in dissertations and other research reports. Dissertations can be evaluated in a way that is more communal and social than in the past (such as in an oral examination of a dissertation), in a broader form - in accordance with the concept of openness and criticism discussed from the start.

\section{References}

Hannula, Mika, Suoranta, J., \& Vadén, T. (2005). Artistic Research: Theories, Methods and Practices. Helsinki and Gothernurg: Academy of Fine Arts and University of Gothernurg.

Lyytikäinen, P. (2012). Rethinking Mimesis: Concepts and Practices of Literary Representation. Cambridge: Cambridge Scholar Publishing.

Merriam-Webster. (2020). Experiential. In Merriam-Webster. Retrieved from https://www.merriam-webster.com/dictionary/experiential 